\title{
Analyses of Changing Disease Patterns and Factors Related to Disease Outcomes in Patients with Crohn's Disease after 7 Years of Follow-up: A Single- center Retrospective Study
}

\section{Dong Yoon Han}

Kyung Hee University Hospital

\section{So Hyun Park}

Gachon University Gil Medical Center

Mirinae Seo

Kyung Hee University Hospital

\section{Seong Jin Park}

Kyung Hee University Hospital

\section{Zi-Xin Liu}

Department of Medicine, Graduate school, Kyung Hee University

Myung-Won You ( $\square$ funfun2020@khu.ac.kr)

Kyung Hee University Hospital

\section{Research Article}

Keywords: Crohn's disease/ complication/diagnosis, recurrence, disease progression, follow-up studies, prognosis

Posted Date: November 19th, 2021

DOI: https://doi.org/10.21203/rs.3.rs-1028093/v1

License: (c) (i) This work is licensed under a Creative Commons Attribution 4.0 International License. Read Full License 


\section{Abstract}

Background: The clinical spectrum and disease course of Crohn's disease (CD) are heterogeneous and difficult to predict based on initial presentation.

Aim: To analyze the long-term disease course and factors leading to poor prognosis of the disease.

Methods: In total, 112 patients with CD who were initially diagnosed or treated at our institution were included. We analyzed their clinical data, disease characteristics according to Montreal classification, endoscopic and computed tomography (CT) examinations at initial visit, and 2-year, 5-year, and last follow-ups. We categorized the long-term disease course into four categories: remission, stable, chronic refractory, and chronic relapsing. Significant factors associated with a poorer prognosis were analyzed.

Results: The median follow-up period was 107 (range, 61-139) months. Complicated disease behavior increased slightly (20.5\% to $26.2 \%)$. Chronic refractory (19.6\%) and relapsing (16.1\%) courses were defined as unfavorable disease course. Two-year disease characteristics were significant factors for unfavorable disease course, and the combination of 2-year perianal disease and 2-year moderate-tosevere $\mathrm{CT}$ activity could predict unfavorable disease course with the highest accuracy $(0.722$, area under the curve $0.768, p<.0001$ ).

Conclusions: One-third of our CD patients showed an unfavorable disease course (35.7\%) and 2-year disease characteristics were significant factors for an unfavorable disease course.

\section{Introduction}

Crohn's disease (CD) is a chronic destructive inflammatory bowel disease that affects young people and is associated with serious morbidity. $C D$ has traditionally been known as a more prevalent disease in the Western world; however, the incidence of $C D$ in Asia increased as did the degree of urbanization in the latter part of the twentieth century [1]. Patients with CD experience a waxing and waning clinical course of relapse and remission and develop cumulative structural damage to the bowel over time [2]. However, the clinical spectrum and disease course of $C D$ are frequently heterogeneous and often difficult to predict based on the initial presentation.

Due to the heterogeneous disease pattern of $C D$, the stratification of patients into clinical subgroups has been proposed for determination and optimization of treatment planning, assessment of disease outcome, and communication between physicians and patients. Thus, the first standardized, clinical classification system to achieve broad acceptance, the Vienna classification, was introduced in 1998, based on patient age at diagnosis, disease location, and disease behavior [3]. The current Montreal classification was proposed by the Working Party at the Montreal World Congress of Gastroenterology as a revision of the Vienna classification. [3] Montreal classification is widely used in both research and clinical practice; however, it has a major drawback in that it shows instability in assessing disease extent/behavior over a period of time, underlining the dynamic nature of CD [4]. Hence, a stratification of 
clinical subgroup according to longitudinal disease course is necessary to reflect changing disease patterns over time. Knowledge about long-term changes of disease course and factors influencing its prognosis can be used as a basis for treatment planning, optimal follow-up and assessment of prognosis.

Therefore, we aimed to investigate disease courses and related factors during long-term treatment and follow-up in patients with $C D$. The primary goal was to evaluate the course of disease in $C D$ patients followed up for over 7 years at our institution. Additionally, we attempted to identify risk factors related to the disease course among clinical, radiological, endoscopic, and treatment-related factors.

\section{Materials And Methods}

\section{Patients}

This retrospective study was approved by the institutional review board (IRB) of Kyung Hee University Hospital, and the requirement for informed consent was waived. We searched electronic medical records (EMRs) and picture archiving and communication system (PACS) images of patients diagnosed with CD from January 2000 to August 2020. The diagnosis of CD was determined according to clinical evaluation and a combination of biochemical, radiological, endoscopic, and histological investigations. $[5,6]$ Patients who were initially diagnosed with $C D$ or treated regularly at our institution were consecutively selected as candidates for our study. Of the 256 patients identified, 85 patients were excluded as their initial records were from before 2009 , and the available information was incomplete with considerable missing data. Hence, 171 patients were left; they were initially diagnosed or treated with CD since January 2009 at our institution. Among these patients, 59 patients were excluded because of the following reasons: 1) no identifiable follow-up data after treatment $(n=14), 2)$ follow-up period less than 5 years $(n=43), 3)$ hard to evaluate disease pattern or activity due to combined disease with tuberculous enteropathy $(n=1)$, and 4) combined disease with ischemic enteropathy $(n=1)$. Finally, a total of $112 C D$ patients were included in this study (Figure 1).

\section{Clinical data analyses}

We investigated clinical information such as age, sex, presence of bowel symptoms, Crohn's disease activity index(CDAl), history of prior bowel or perianal operation, nonsmoker or former/current smoker, presence of family history of inflammatory bowel disease, disease duration from the initial to the last visit, and presence of extra-intestinal manifestations including arthritis, Raynaud phenomenon, sclerosing cholangitis, or ankylosing spondylitis. Information regarding treatment such as usage of systemic steroids at initial diagnosis, usage of immunosuppressants (IMS) including azathioprine, mercaptopurine, and methotrexate; usage of biologics and its type (including infliximab, adalimumab, golimumab, vedolizumab, ustekinumab, tofacitinib, and filgotinib), time point of initial usage of biologics since diagnosis (no use, initial use, first use within 2-year follow-up, after 2-year and within 5-year follow-up, after 5-year follow-up), single or combination therapy of IMS with biologics were recorded. 'Regimen change' was defined as change of IMS to biologics, 'change of biologics' was defined as change of one 
type of biologics to another type of biologics, and 'dose intensification' was defined as a dose increase of 2-fold the usual dose. These treatment data were recorded.

\section{Radiologic and endoscopic analyses of disease pattern}

Two abdominal radiologists (with 13 years and 8 years' experience in abdominal radiology) reviewed contrast-enhanced computed tomography (CECT) images and recorded CT activity scores. Although several CT scoring systems have been adapted in other studies [7-9], none of these have been credibly validated and grading of disease severity was only partially quantified without cut-off values of grades. Therefore, we generated a modified CT scoring system similar to the previously reported MR activity scoring system [10], with reference to CT features evaluated on other reported CT scoring systems [11]. The following CT features were recorded for each patient: wall thickness, wall enhancement with enhancement pattern, total length of the diseased segment, presence of comb sign (vascular enlargement of the vasa recta), and the presence of any complications, including abscess, fistula, or severe stenosis. Stricturing and penetrating diseases were defined according to consensus recommendations [12]. According to the sum of the total score measured with these features, one of the four categories of no activity, mild, moderate, or severe activity was determined (Table 1). In cases involving more than one lesion, the lesion with the highest activity score was selected for categorization. In each patient, the two reviewers evaluated two CECT examinations, namely initial and 2-year follow-up CT examinations. The scoring of CT activity was independently performed by each reviewer with a 2-week interval between the evaluation of disease pattern and endoscopic activity, and the interreader agreement was assessed. The disease pattern was evaluated according to the Montreal classification [13], based on CECT and endoscopic features. Disease location was classified into one of three categories L1, ileal; L2, colic; and L3, ileocolic disease. Disease behavior was classified into one of four categories B1, non-stricturing nonpenetrating inflammatory; B2, stricturing; B3, penetrating; and B4, combined stricturing and penetrating disease. The presence of upper gastrointestinal tract involvement (L4 lesion) and presence of perianal lesions $(P)$ were separately recorded. In case of no visible active or chronic lesion, disease location and behavior were recorded as 'none'. The presence of endoscopic activity was also recorded based on the endoscopic images and reports. The evaluations of endoscopic activity and disease patterns were performed by the two reviewers, who reached a consensus.

\section{Classification of disease course during the whole follow-up period}

Disease course was classified into four categories: remission, improved and stable, chronic refractory and chronic relapsing. 'Remission' was defined as more than two of three categories among clinical remission, endoscopic remission, and CT activity score 0-1 at the last follow-up. 'Clinical remission' was defined as decrease in severity of bowel symptoms or CDAK 150 . 'Endoscopic remission' was defined as achievement of complete mucosal normalization [14]. The individual case was classified as remission if the disease activity decreased without any residual activity after modification of medical treatment such as regimen change or dose optimization, even if there was an increase in the severity of disease activity during the follow-up. 'Improved and stable' was defined as an individual in clinical remission with residual 
endoscopic activity or residual CT activity more than 2. 'Chronic refractory' was defined as wax and wane, but persistent clinical symptoms, and radiologic/endoscopic activities, without remission. 'Chronic relapsing' was defined as more than once relapse in bowel symptoms or radiologic/endoscopic activities for each treatment regimen. 'Relapse' was defined as an aggravation of bowel symptoms, CT or endoscopic activities leading to the need for more intensive medical and/or surgical treatment after achieving remission. We modified these definitions from a previous report [15], adding radiological and endoscopic activities to overcome mismatched cases between clinical symptoms and radiological/endoscopic findings, especially in cases with small bowel lesions.

\section{CT techniques}

CT examinations were performed using one of the following multidetector CT scanners: 16-channel Lightspeed from GE healthcare $(n=111), 64$-channel Brilliance $(n=66), 128$-channel Ingenuity $(n=81)$ from Philips Healthcare, and 64-channel Aquilion Toshiba $(n=62)$ at four time points (initial visit and 2-year, 5year, and last follow-up). The scanning parameters were as follows: a peak voltage of $120 \mathrm{kVp}$; a tube current-time product of 150-200 mAs with automated tube current modulation; a 2.5 5-mm slice thickness with a 3-mm reconstruction interval; a field of view of $300-380 \mathrm{~mm}$; a gantry rotation time of 0.5-0.6 s; detector configuration of $0.625 \mathrm{~mm}$; z-axis coverage of 24,40 , and $40 \mathrm{~mm}$; pitch $0.9,0.7$ and 0.8 $\mathrm{s}$; table speeds of $43.2,47.5$ and $63.8 \mathrm{~mm}$ per second; and a single breath-hold helical acquisition time of 9-10 s for 16-64-, and 128-channel CT exams. Among the total CT exams ( $n=335)$, two-thirds were small bowel enterography $(n=241,72 \%)$, and the remaining one-third was conventional abdomen-pelvis CT $(n=92,27 \%)$. The CT protocol for small bowel enterography was as follows: patients were asked to drink $1500 \mathrm{~mL}$ of $3 \%$ polyethylene glycol solution (Harprep, Pharmbio, Korea) $45 \mathrm{~min}$ before scanning for maximum distension of the small bowel. For contrast enhancement, $120 \mathrm{~mL}$ of nonionic contrast medium (Iomeprol 350, Bracco Imaging) was injected intravenously at a rate of $2 \mathrm{ml} / \mathrm{s}$, followed by $20 \mathrm{ml}$ saline flushing. The scanning delay was $60 \mathrm{~s}$ for the portal phase, and additional coronal reformatted images were obtained.

\section{Statistical analyses}

Comparisons of differences in categorical and continuous data were performed using Fisher's exact probability test or Wilcoxon rank sum test, as appropriate. The association of variables with disease course was investigated using univariate and multivariate logistic regression analyses. All variables with $P$ values $<0.1$, from univariate regression analysis, were included in the multivariate model. Adjustment with the firth's method was used for multivariate regression analysis. Receiver operating characteristic (ROC) curve analyses were performed using the selected disease-related variables in the multivariate logistic regression. To perform time-to-even analyses, we used the log-rank test or Cox proportional hazards model, as appropriate. The inter-reader agreement was assessed using Cohen's kappa value, and the interpretation of kappa values was as follows: 0.21-0.4, fair agreement; 0.41-0.6, moderate agreement; 0.61-0.8, substantial agreement; 0.81-0.99, near perfect agreement. Statistical analyses were performed using SPSS version 26 (IBM, New York, USA), SAS version 14.3 (SAS Institute Inc., NC, USA), and Medcalc 
version 14.8.1 (Ostend, Belgium) were used. A two-tailed test for statistical significance was performed, and the level of statistical significance was set at $p<0.05$.

\section{Results}

\section{Analyses of disease course during long-term follow-up period}

\section{Disease course and outcomes}

The median follow-up period was 107 months (range, 61-139 months). Among the four categories of disease course, remission was $27.7 \%$ (31/112), stable was $36.6 \%(41 / 112)$, refractory was $19.6 \%$ (22/112), and relapsing was $16.1 \%$ (18/112). Therefore, the benign disease course was $64.3 \%(72 / 112)$, and the unfavorable disease course was $35.7 \%$ (40/112). Sixteen patients underwent bowel surgery $(14.3 \%)$, and 9 patients underwent perianal surgery (8\%). The median time to relapse was 103.5 months (range, 41-139 months) and the median time to bowel surgery was 104 months (range, 1-139 months).

\section{Changes in disease patterns}

Figure 2 shows the changes in disease patterns over time. Disease location was relatively stable, but the proportion of L3 disease decreased, instead of the increased proportion of no lesions. Complicated disease behavior (B2-4) slightly increased from $20.5-26.1 \%$, but $17.8 \%$ showed no lesions at the last follow-up. Both L4 lesions and perianal disease gradually decreased, as did active endoscopic lesions. The kappa value of interreader agreement for CT activity scoring was 0.51 (standard error: 0.07 ) indicating moderate agreement. The majority of patients showed moderate-to-severe CT activity scores at the initial visit; however, the proportion of moderate and severe grades of CT activity decreased from $91.1-46.2 \%$ at the last follow-up (Figure 2).

\section{Analyses of disease characteristics for unfavorable disease course}

Comparison of clinical and disease characteristics between benign controlled and unfavorable disease course

The mean age of study population was $24.73 \pm 9.4$ (range, 12-51) and $82.1 \%(92 / 112)$ of patients were male. Prior bowel operation and prior perianal operation history were present in $5.4 \%(6 / 112)$ and $21.4 \%$ (24/112) of patients, respectively. Nonsmoker was $23.2 \%(26 / 112)$, former smoker was $1.8 \%(2 / 112)$ and current smoker was $9.8 \%(11 / 112)$, but the majority was unknown $(65.2 \%)$. Systemic steroids were used in only $5.4 \%(6 / 112)$ of patients at the initial visit. Most of the patients received immunosuppressants (IS) $(96.4 \%, 108 / 112)$, more than one kind of biologics $(79.5 \%, 89 / 112)$, and combination therapy $(64.3 \%$, 
74/112). The time points of the first usage of biologics were evenly distributed between the initial and later than the 5 -year follow-up. About $19 \%$ of patients experienced dose intensification, $55.4 \%$ switched from IS to biologics, and 31.3\% switched from one type to another type of biologics (Supplementary Table 1).

Most of the patients in the benign disease course received none or one type of biologics (90.28\%), while most of the patients in the unfavorable disease course received one or more types of biologics (95\%, $p<.0001)$. The time points of first usage of biologics were different in each group; patients with benign courses mostly started biologics within the 5 -year follow-up (31.4\%), while patients with unfavorable courses mostly started from the initial visit $(34.2 \%, p=0.012)$. A higher percentage of patients experienced dose intensification ( $40 \%$ vs. $6.94 \%$ ) and switched from one to another type of biologics (65\% vs. $12.5 \%$ ) in the unfavorable course group.

At the initial visit, the most frequent disease location was in the ileocolon (L3, 74.1\%) and mostly represented B1 type of disease behavior (79.5\%). L4 lesions were present in $42.9 \%$ (48/112), perianal disease was present in $71.4 \%$ (80/112), and the CT activity score was mostly moderate $(30.4 \%)$ or severe $(60.7 \%)$. There were no significant differences in these variables between the two groups at the initial visit. At the 2-year follow-up, the overall distributions of disease location and behavior were similar to those at the initial visit. However, the percentage of complicated disease behavior (B2-4) in the unfavorable disease course group was higher than that in the benign disease course group $32.26 \%$ vs. $12.5 \%, p=0.045)$. The percentages of $L 4$ lesions and perianal lesions were decreased $(19.6 \%$ and $36.6 \%$, respectively), and the proportion of moderate-to-severe grades of CT activity decreased (40.2\%). However, patients with an unfavorable disease course showed more prevalent perianal lesions $(68.75 \%$ vs. $39.58 \%$, $p=0.013)$ and moderate or severe grades of CT activity $(82.76 \%$ vs. $48.84 \%, p<.001)$. The percentage of endoscopically active lesions also decreased (44.6\%) (Supplementary Table 2).

\section{Significant factors for unfavorable disease course}

In the multivariate logistic regression analysis, 2-year complicated disease behavior (OR 3.87, 95\% Cl 1.14-13.16), 2-year perianal disease (OR 3.43,95\% Cl 1.24-9.51), and 2-year moderate to severe grades of CT activity (OR 4.95, 95\% Cl 1.55-15.83) were the significant factors among disease characteristics for unfavorable disease course (Table 2). One or more biologics use (OR 6.07, 95\% Cl 1.51-24.34), two or more biologics use (OR 12.58, 95\% $\mathrm{Cl} 4.52-34.97$ ), biologics change (OR 12.38, 95\% $\mathrm{Cl}$ 4.54-33.75), dose intensification (OR 7.81, 95\% Cl 2.59-23.51) and combination therapy (OR 3.31, 95\% Cl 1.30-8.43) were the significant factors among treatment-related variables for unfavorable disease course. All variables related to initial disease pattern showed no significant odds ratio for disease course.

\section{ROC analyses for unfavorable disease course using selected disease parameters}

We analyzed ROC curves for unfavorable disease course using the selected disease-related factors (Table 3, Figure 3). The three disease-related factors for unfavorable disease course: 2-year B2-4, 2-year perianal 
disease, and 2-year moderate to severe CT scores were used for the generation of diagnostic prediction models. Among 7 models, 2-year perianal lesion with 2-year moderate to severe CT scores model showed the highest diagnostic accuracy (0.722) and area under the curve (AUC, 0.768, $p<.0001)$, comparable to those of combination of three variables (accuracy: 0.708 , AUC: $0.779, P<.0001$ ).

\section{Discussion}

In this study, CD patients showed gradually decreasing L4 lesion, perianal disease, active endoscopic lesions and moderate to severe CT activity; however, about half of the patients showed persistent moderate to severe CT (46.2\%) and endoscopic activities (50.6\%). Disease locations were relatively stable over time, with majority consisting of L1 and L3 lesions. Proportion of complicated disease behavior was slightly increased over time (initial: $20.5 \%$ to last: $26.2 \%$ ), however insignificant, compared to previous studies: $42.7 \sim 50.7 \%[16,17]$, and a recent study reporting 31\% [18]. Although initial proportion of complicated disease behavior was slightly higher than previous studies $(20.5 \%$ vs. $17-18.6 \%)[16,18]$, it was lower for last follow-up than reported in these studies (26.2\% vs. 31-42.7\%). Both Ye et al.'s [17] and our studies show a better clinical course of the disease in Korean CD patients than western patients.

We found approximately two thirds of patients showing benign controlled disease course, while one third showed unfavorable course such as chronic refractory or relapsing diseases. Additionally, we found that 2-year disease patterns, rather than the initial manifestation, were the significant factors for unfavorable disease course. These findings correlate with those of previous studies. Beaugerie et al. also reported that clinical prognosis can be better determined during the course of the first 2 years than with the clinical parameters present at the time of onset [19]. Another study with inception cohort from Denmark showed that relapse rates within 2 years after the diagnosis significantly correlated with the incidence of relapses in the following 5 years whereas no useful clinical factors within a year after the diagnosis was identified for the prediction of clinical progress [20]. Apart from these studies from Western countries, a study conducted with Japanese cohort reported that prediction of 11- to 15-year clinical course is possible by using clinical factors during the first year after starting treatment, and also determining the effectiveness of the initial treatment [21]. Taken together, it may be stated that treatment response or effectiveness after initial treatment determines long-term disease course rather than initial clinical or radiologic presentations at the time of disease onset.

We additionally analyzed diagnostic prediction models using the 2-year disease-related factors. We found that 2-year perianal disease with moderate to severe CT activity scores were useful factors to predict unfavorable disease course with the highest accuracy. The proportion of perianal disease was quite higher than previous study from South Korea [17] in our study population $(71.4 \%$ vs. $46.8 \%)$ and this rate gradually decreased over time to $44.2 \%$ at the last follow-up. Quaz et al. also reported perianal disease is associated with disease severity. [22] Perianal disease is a well-known factor associated with poor prognosis [18]. In this study, we found that disease severity determined with CT activity scores can be the significant factor for disease course in combination of perianal disease. Although MRI grading is a more validated method for assessment of disease activity, CT and MRI shows comparable high accurate 
grading estimates according to meta-analysis [11]. In our institution, most of the included CD patients underwent CT exams during disease monitoring, and therefore, we generated CT-based disease activity scoring system to assess radiologic disease activity in a quantitative manner.

There are some limitations in this study. First, this is a retrospective study and has its inherent flaws. There were missing or incomplete data regarding clinical information such as smoking status, family history, and extraintestinal manifestation. Therefore, we excluded these data from the logistic or Cox regression analyses. Second, a relatively small number of patients were analyzed. Due to incomplete old clinical data, we confined eligible patients to those who were diagnosed after 2009, and excluded patients who were diagnosed before 2009. Third, variable follow-up periods among the included CD patients. Not all patients at initial visit underwent CT or endoscopic exam at the next follow-up. Therefore, a decreased number of data were obtained during 2-year, 5-year and last follow-ups compared with those of initial visits. Fourth, heterogeneous $\mathrm{CT}$ techniques were used to obtain CT scans of included patients during the long-term follow-up period. Fifth, CT scoring in this study was not fully validated. We need to analyze CT exams quantitatively, however, there is no credibly validated CT scoring system, and therefore, we developed a new CT scoring system with reference to previous response assessment studies [11, 23]. Sixth, included patients received heterogeneous treatments. Most of the patients received IS (96.4\%) and this included three types of IS such as azathioprine, 6-mercaptopurine and methotrexate although most received azathioprine (93.8\%). About $80 \%$ of included patients received biologics and this included seven different types of biologics.

\section{Conclusions}

CD patients with initially active disease showed gradual improvement in disease activities during longterm follow-up with only $26.2 \%$ of complicated disease behavior at the end of the follow-up period.

However, one third of patients showed unfavorable disease course such as chronic refractory or relapsing diseases, and the 2-year follow-up disease characteristics, instead of the initial manifestations, were the significant factors for unfavorable disease course.

\section{Declarations}

\section{Ethics approval and consent to participate}

The study was approved by the ethics committee of the Kyung Hee University Hospital.

\section{Consent for publication}

Not applicable

\section{Availability of data and materials}


Datasets used and analyzed during the study are available upon reasonable request from the corresponding author.

\section{Competing interests}

The authors declare that they have no competing interests

\section{Funding}

Not applicable

\section{Authors' contributions}

H.Y, data collection and investigation; S.P and M.S, methodology and data analyses; Z.L, assisted data collection, S.P, supervised the study including data analysis, methodology, and critical revision of manuscript; M.Y, designed and supervised the study, drafted and revised manuscript. All authors had read and approved the manuscript.

\section{Acknowledgements}

Not applicable

\section{References}

1. Ng SC, Tang W, Ching JY, Wong M, Chow CM, Hui AJ, Wong TC, Leung VK, Tsang SW, Yu HH et al: Incidence and phenotype of inflammatory bowel disease based on results from the Asia-pacific Crohn's and colitis epidemiology study. Gastroenterology 2013, 145(1):158-165 e152.

2. Pariente B, Cosnes J, Danese S, Sandborn WJ, Lewin M, Fletcher JG, Chowers Y, D'Haens G, Feagan BG, Hibi T et al: Development of the Crohn's disease digestive damage score, the Lemann score. Inflammatory bowel diseases 2011, 17(6):1415-1422.

3. Gasche C, Scholmerich J, Brynskov J, D'Haens G, Hanauer SB, Irvine EJ, Jewell DP, Rachmilewitz D, Sachar DB, Sandborn WJ et al: A simple classification of Crohn's disease: report of the Working Party for the World Congresses of Gastroenterology, Vienna 1998. Inflammatory bowel diseases 2000, 6(1):8-15.

4. Gajendran M, Loganathan P, Catinella AP, Hashash JG: A comprehensive review and update on Crohn's disease. Disease-a-month: DM 2018, 64(2):20-57.

5. Van Assche G, Dignass A, Panes J, Beaugerie L, Karagiannis J, Allez M, Ochsenkuhn T, Orchard T, Rogler G, Louis E et al: The second European evidence-based Consensus on the diagnosis and 
management of Crohn's disease: Definitions and diagnosis. Journal of Crohn's \& colitis 2010, 4(1):727.

6. Loftus EV, Jr., Silverstein MD, Sandborn WJ, Tremaine WJ, Harmsen WS, Zinsmeister AR: Crohn's disease in Olmsted County, Minnesota, 1940-1993: incidence, prevalence, and survival. Gastroenterology 1998, 114(6):1161-1168.

7. Kolkman JJ, Falke THM, Roos JC, Van Dijk DH, Bannink IMJ, Den Hollander W, Cuesta MA, Peña AS, Meuwissen SGM: Computed tomography and granulocyte scintigraphy in active inflammatory bowel disease. Digestive Diseases and Sciences 1996, 41(4):641-650.

8. Mao R, Gao X, Zhu Z-h, Feng S-t, Chen B-I, He Y, Cui Y, Li Z-p, Hu P-j, Chen M-h: CT Enterography in Evaluating Postoperative Recurrence of Crohn's Disease after lleocolic Resection: Complementary Role to Endoscopy. Inflammatory bowel diseases 2013, 19(5):977-982.

9. Mohamed AM, Amin SK, El-Shinnawy MA, Elfouly A, Baki AH: Role of CT enterography in assessment of Crohn's disease activity: Correlation with histopathologic diagnosis. The Egyptian Journal of Radiology and Nuclear Medicine 2012, 43(3):353-359.

10. Tielbeek JAW, Bipat S, Boellaard TN, Nio CY, Stoker J: Training readers to improve their accuracy in grading Crohn's disease activity on MRI. European Radiology 2014, 24(5):1059-1067.

11. Puylaert CAJ, Tielbeek JAW, Bipat S, Stoker J: Grading of Crohn's disease activity using CT, MRI, US and scintigraphy: a meta-analysis. European radiology 2015, 25(11):3295-3313.

12. Bruining DH, Zimmermann EM, Loftus EV, Jr., Sandborn WJ, Sauer CG, Strong SA, Society of Abdominal Radiology Crohn's Disease-Focused P: Consensus Recommendations for Evaluation, Interpretation, and Utilization of Computed Tomography and Magnetic Resonance Enterography in Patients With Small Bowel Crohn's Disease. Gastroenterology 2018, 154(4):1172-1194.

13. Silverberg MS, Satsangi J, Ahmad T, Arnott ID, Bernstein CN, Brant SR, Caprilli R, Colombel JF, Gasche $\mathrm{C}$, Geboes $\mathrm{K}$ et al: Toward an integrated clinical, molecular and serological classification of inflammatory bowel disease: report of a Working Party of the 2005 Montreal World Congress of Gastroenterology. Can J Gastroenterol 2005, 19 Suppl A:5A-36A.

14. Ma C, Fedorak RN, Kaplan GG, Dieleman LA, Devlin SM, Stern N, Kroeker KI, Seow CH, Leung Y, Novak $\mathrm{KL}$ et al: Long-term Maintenance of Clinical, Endoscopic, and Radiographic Response to Ustekinumab in Moderate-to-Severe Crohn's Disease: Real-world Experience from a Multicenter Cohort Study. Inflammatory bowel diseases 2017, 23(5):833-839.

15. Solberg IC, Vatn MH, Hoie O, Stray N, Sauar J, Jahnsen J, Moum B, Lygren I, Group IS: Clinical course in Crohn's disease: results of a Norwegian population-based ten-year follow-up study. Clin Gastroenterol Hepatol 2007, 5(12):1430-1438.

16. Thia KT, Sandborn WJ, Harmsen WS, Zinsmeister AR, Loftus EV, Jr.: Risk factors associated with progression to intestinal complications of Crohn's disease in a population-based cohort. Gastroenterology 2010, 139(4):1147-1155.

17. Ye BD, Yang SK, Cho YK, Park SH, Yang DH, Yoon SM, Kim KJ, Byeon JS, Myung SJ, Yu CS et al: Clinical features and long-term prognosis of Crohn's disease in Korea. Scand J Gastroentero/ 2010, 
45(10):1178-1185.

18. Rackovsky O, Hirten R, Ungaro R, Colombel JF: Clinical updates on perianal fistulas in Crohn's disease. Expert review of gastroenterology \& hepatology 2018, 12(6):597-605.

19. Beaugerie L, Le Quintrec Y, Paris JC, Godchaux JM, Saint-Raymond A, Schmitz J, Ricour C, Haddak $\mathrm{M}$, Diday E: Testing for course patterns in Crohn's disease using clustering analysis. Gastroenterol Clin Biol 1989, 13(12):1036-1041.

20. Munkholm P, Langholz E, Davidsen M, Binder V: Disease activity courses in a regional cohort of Crohn's disease patients. Scand J Gastroenterol 1995, 30(7):699-706.

21. Oriuchi T, Hiwatashi N, Kinouchi Y, Takahashi S, Takagi S, Negoro K, Shimosegawa T: Clinical course and longterm prognosis of Japanese patients with Crohn's disease: predictive factors, rates of operation, and mortality. J Gastroentero/ 2003, 38(10):942-953.

22. Ouaz A, Fekih M, Labidi A, Ben Mustapha N, Serghini M, Zouiten L, Boubaker J, Filali A: Changes of Crohn's disease phenotype over time. La Tunisie medicale 2016, 94(6):167-170.

23. Makanyanga JC, Pendse D, Dikaios N, Bloom S, McCartney S, Helbren E, Atkins E, Cuthbertson T, Punwani S, Forbes A et al: Evaluation of Crohn's disease activity: initial validation of a magnetic resonance enterography global score (MEGS) against faecal calprotectin. Eur Radiol 2014, 24(2):277-287.

\section{Tables}

Table 1

Modified CT scoring system 


\begin{tabular}{|c|c|c|c|c|}
\hline & 0 & 1 & 2 & 3 \\
\hline Wall thickness & $3 \mathrm{~mm} \geq$ & $4-5 \mathrm{~mm}$ & $6-7 \mathrm{~mm}$ & $8 \mathrm{~mm} \leq$ \\
\hline $\begin{array}{l}\text { Wall } \\
\text { enhancement } \\
\text { (compared to } \\
\text { adjacent } \\
\text { vessels) }\end{array}$ & Normal & $\begin{array}{l}\text { Mild } \\
\text { minor increase, but less than } \\
\text { vessels }\end{array}$ & $\begin{array}{l}\text { Moderate } \\
\text { moderate increase } \\
\text { but } \\
\text { less than vessels }\end{array}$ & $\begin{array}{l}\text { Severe } \\
\text { marked } \\
\text { increase, } \\
\text { similar } \\
\text { to vessels }\end{array}$ \\
\hline $\begin{array}{l}\text { Enhancement } \\
\text { pattern }\end{array}$ & Normal & 'Homogenous & ${ }^{\square}$ Mucosal & $\epsilon_{\text {Layered }}$ \\
\hline Disease length & None & $5 \mathrm{~cm}$ & $5-15 \mathrm{~cm}$ & $15 \mathrm{~cm} \leq$ \\
\hline Comb sign & No & Yes & & \\
\hline \multicolumn{5}{|c|}{ None: no signs of active disease } \\
\hline \multicolumn{5}{|c|}{ Mild: total score $6 \geq$, no features with score 3} \\
\hline \multicolumn{5}{|c|}{ Moderate: total score $7-10$ or presence of any one feature with score $\geq 3$} \\
\hline \multicolumn{5}{|c|}{$\begin{array}{l}\text { Severe: total score } \geq 11 \text { or presence of at least one complication including abscess, fistula or } \\
\text { stenosis. }\end{array}$} \\
\hline \multicolumn{5}{|c|}{$\begin{array}{l}\text { I homogenous enhancement pattern is defined as one-layered bowel wall with } \\
\text { enhancement }\end{array}$} \\
\hline \multicolumn{5}{|c|}{$\begin{array}{l}\text { Qmucosal enhancement pattern is defined as two-layered bowel wall with inner layer } \\
\text { enhancement }\end{array}$} \\
\hline \multicolumn{5}{|c|}{$\begin{array}{l}€ \text { layered enhancement pattern is defined as three-layered bowel wall with inner and } \\
\text { outer layer enhancements and hypo-enhancement of middle layer. }\end{array}$} \\
\hline
\end{tabular}

Table 2

Multivariate regression analyses for unfavorable disease course 


\begin{tabular}{|c|c|c|c|}
\hline & $\operatorname{Exp}(B)^{9}$ & 95\% confidence interval $(\mathrm{Cl})$ & p-value \\
\hline Initial L4 lesion & 1.6 & $0.71-3.60$ & 0.255 \\
\hline Initial disease behavior: B2-4 & 0.99 & $0.35-2.80$ & 0.990 \\
\hline Initial perianal lesion & 1.49 & $0.58-3.84$ & 0.412 \\
\hline $\begin{array}{l}\text { Initial moderate to severe } \\
\text { CT activity score }\end{array}$ & 3.65 & $0.56-23.83$ & 0.176 \\
\hline Initial endoscopic activity & 0.68 & $0.11-4.35$ & 0.687 \\
\hline 2-year L4 lesion & 2.33 & $0.83-6.56$ & 0.109 \\
\hline 2-year disease behavior: B2-4 & 3.87 & $1.14-13.16$ & 0.030 \\
\hline 2-year perianal disease & 3.43 & $1.24-9.51$ & 0.017 \\
\hline $\begin{array}{l}\text { 2-year moderate to severe } \\
\text { CT activity score }\end{array}$ & 4.95 & $1.55-15.83$ & 0.007 \\
\hline 2-year endoscopic activity & 2.03 & $0.71-5.75$ & 0.185 \\
\hline Use of immunosuppressants (IS) & 1.18 & $0.13-10.58$ & 0.885 \\
\hline Use of 1 or more biologics & 6.07 & $1.51-24.34$ & 0.011 \\
\hline Use of 2 or more biologics & 12.58 & $4.52-34.97$ & $<.0001$ \\
\hline First use of biologics within 2 years & 0.48 & $0.21-1.07$ & 0.072 \\
\hline Biologics change & 12.38 & 4.54-33.75 & $<.0001$ \\
\hline Dose intensification & 7.81 & $2.59-23.51$ & $<.0001$ \\
\hline Combination therapy & 3.31 & $1.30-8.43$ & 0.012 \\
\hline
\end{tabular}

Table 3

ROC curve for sensitivity analyses for unfavorable disease course 


\begin{tabular}{|c|c|c|c|c|c|}
\hline & Sensitivity & Specificity & Accuracy & $\begin{array}{l}\mathrm{AUC}^{€} \\
(\mathrm{Cl})\end{array}$ & $\begin{array}{l}\mathrm{p}- \\
\text { value }\end{array}$ \\
\hline $\begin{array}{l}\text { 2-year disease behavior } \\
\text { : B2-4 }\end{array}$ & $\begin{array}{l}0.621 \\
(18 / 29)\end{array}$ & $\begin{array}{l}0.628 \\
(27 / 43)\end{array}$ & $\begin{array}{l}0.625 \\
(45 / 72)\end{array}$ & 0.625 & 0.07 \\
\hline 2-year perianal disease & $\begin{array}{l}0.793 \\
(23 / 29)\end{array}$ & $\begin{array}{l}0.558 \\
(24 / 43)\end{array}$ & $\begin{array}{l}0.653 \\
(47 / 72)\end{array}$ & 0.673 & 0.007 \\
\hline $\begin{array}{l}\text { 2-year moderate to severe CT activity } \\
\text { score }\end{array}$ & $\begin{array}{l}0.759 \\
(22 / 29)\end{array}$ & $\begin{array}{l}0.628 \\
(27 / 43)\end{array}$ & $\begin{array}{l}0.681 \\
(49 / 72)\end{array}$ & 0.686 & 0.004 \\
\hline 2-year B2-4+ 2-year P & $\begin{array}{l}0.655 \\
(19 / 29)\end{array}$ & $\begin{array}{l}0.651 \\
(28 / 43)\end{array}$ & $\begin{array}{l}0.653 \\
(47 / 72)\end{array}$ & 0.724 & 0.0002 \\
\hline 2-year B2-4+ 2-year CT score & $\begin{array}{l}0.724 \\
(21 / 29)\end{array}$ & $\begin{array}{l}0.651 \\
(28 / 43)\end{array}$ & $\begin{array}{l}0.681 \\
(49 / 72)\end{array}$ & 0.731 & 0.0001 \\
\hline 2-year P+ 2-year CT score & $\begin{array}{l}0.793 \\
(23 / 29)\end{array}$ & $\begin{array}{l}0.674 \\
(29 / 43)\end{array}$ & $\begin{array}{l}0.722 \\
(52 / 72)\end{array}$ & 0.768 & $<.0001$ \\
\hline 2-year B2-4+2-year P+2-year CT score & $\begin{array}{l}0.759 \\
(22 / 29)\end{array}$ & $\begin{array}{l}0.674 \\
(29 / 43)\end{array}$ & $\begin{array}{l}0.708 \\
(51 / 72)\end{array}$ & 0.779 & $<.0001$ \\
\hline \multicolumn{6}{|c|}{$\begin{array}{l}\text { B2-4, complicated disease behavior; } \mathrm{P} \text {, perianal disease; AUC, area under the curve; } \mathrm{C} \\
\text { confidence interval } \\
€ \text { Adjusted by sex, age, prior operation history, prior perianal operation history, and } \\
\text { initial variables. }\end{array}$} \\
\hline
\end{tabular}

\section{Figures}


Retrospectively collected patients diagnosed with Crohn's disease until August 2020, based on electronic medical record (EMR) and picture archiving and communication system(PACS) $(n=256)$

Initial diagnosis or treatment before $2009(n=85)$

Initially diagnosed or treated patients since January 2009 at our institution $(n=171)$

$\longrightarrow$\begin{tabular}{l|} 
Excluded patients ( $n=59$ ) \\
$N=14$, no treatment or no follow-up data after treatment \\
$N=43$, less than 5 -year follow-up period \\
$N=1$, combined disease with tuberculous enteropathy \\
$N=1$, combined disease with ischemic enteropathy
\end{tabular}

Finally included Crohn's disease patients $(n=112)$

Figure 1

Patient selection 

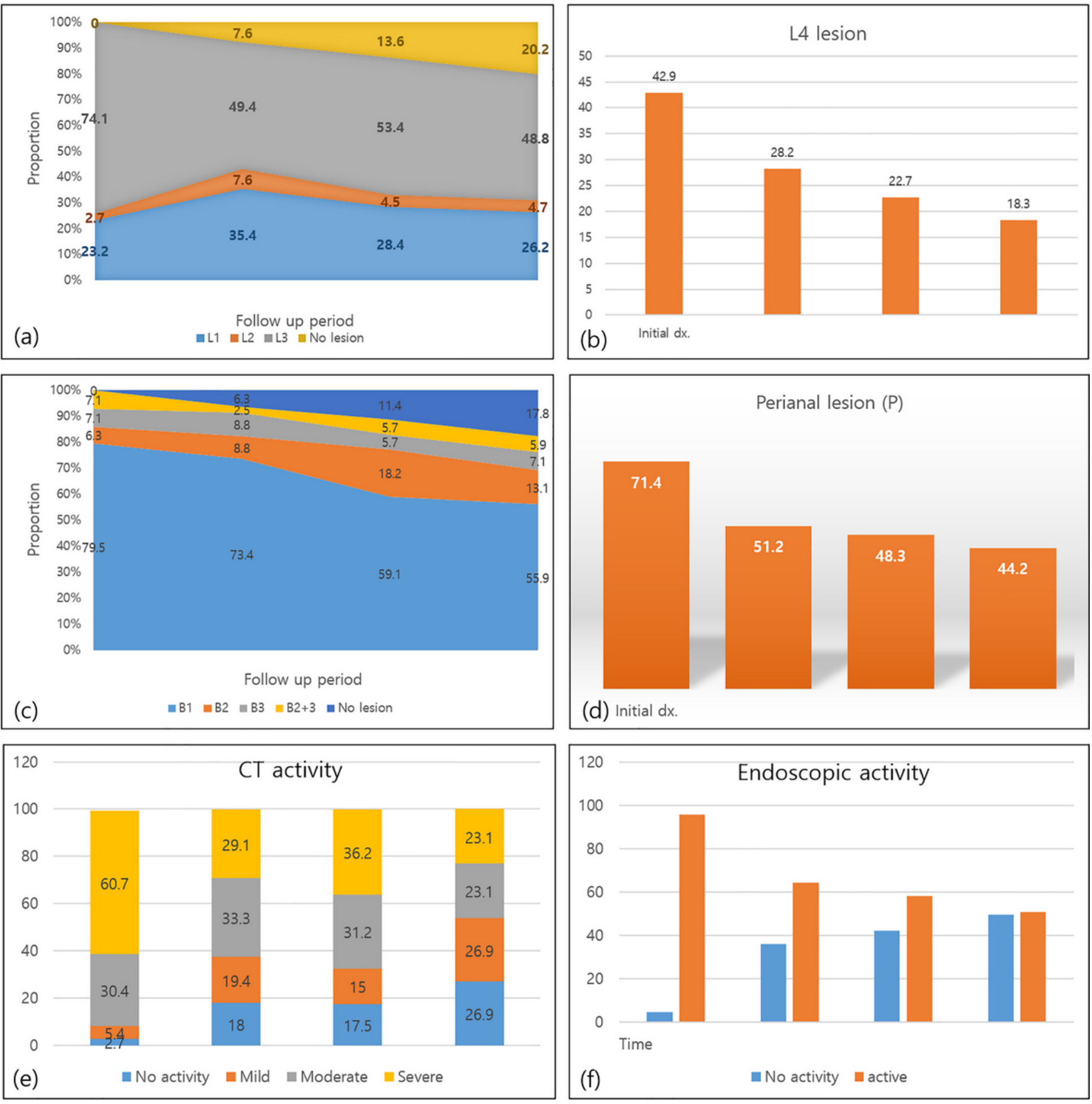

\section{Figure 2}

Changes in disease pattern (a) Disease location from initial diagnosis to the last follow-up (b) Percentage of presence of L4 lesion according to Montreal classification (c) Disease behavior from initial to the last follow-up (d) Percentage of perianal disease according to Montreal classification (e) Disease activity evaluated on CT images (f) Disease activity evaluated on endoscopy 


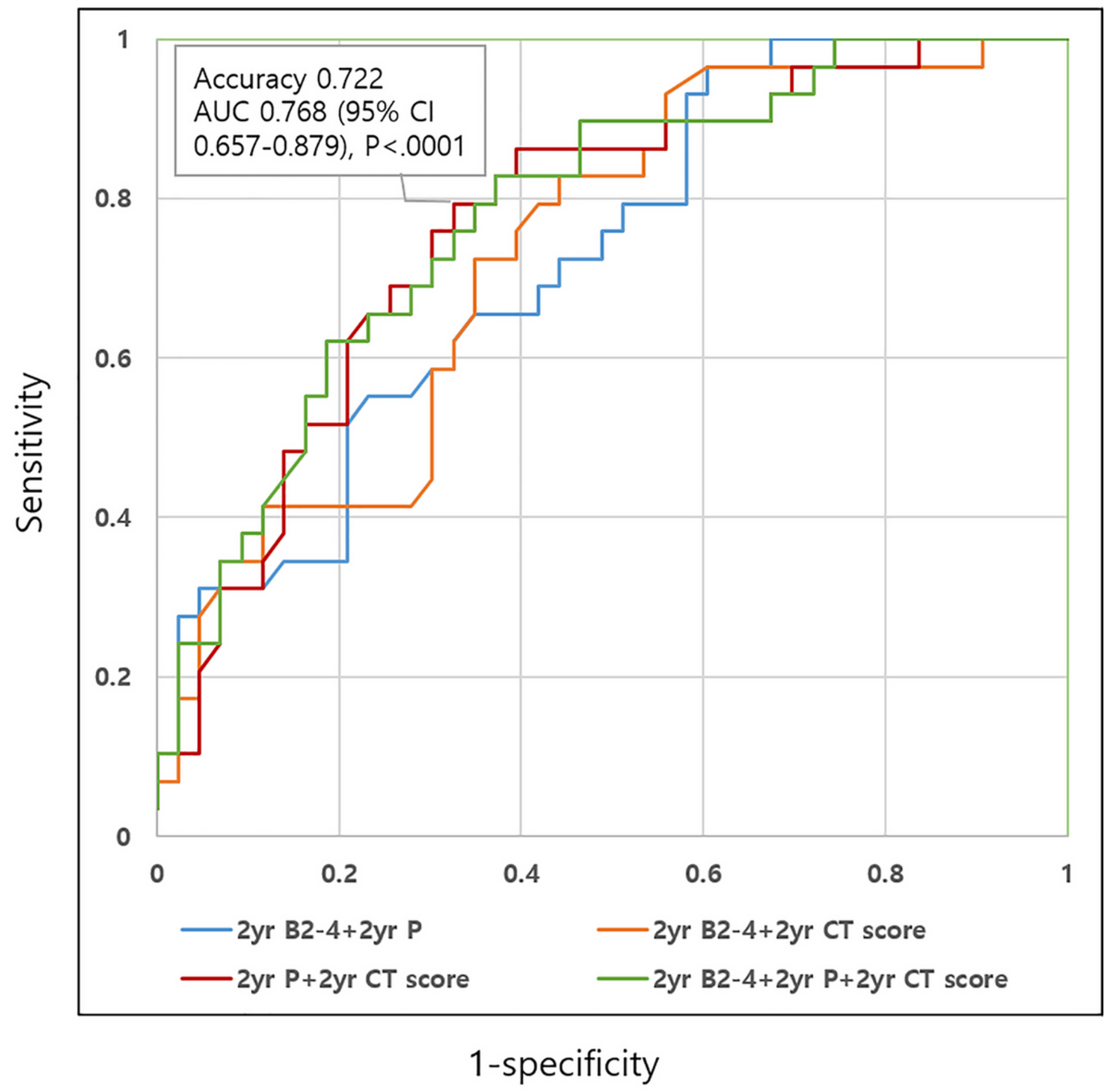

Figure 3

ROC analyses for unfavorable disease course using selected disease parameters Combining two or three variables among 2-year B2-4, 2-year perianal disease, and 2-year moderate to severe CT score, 2-year perianal disease with 2-year moderate to severe CT activity scores showed the highest accuracy and AUC (red line, $0.768, p<.0001$ ) as well as combination of 2-year B2-4, 2-year perianal disease, and 2-year moderate to severe CT scores (green line, $0.779, \mathrm{p}<.0001$ ). 


\section{Supplementary Files}

This is a list of supplementary files associated with this preprint. Click to download.

- SupplementaryTables.docx 